\title{
Testing the durability and function of road traffic management devices
}

\author{
Lukasz Jeliński ${ }^{1, *}$, Joanna Wachnicka $^{1}$, Jan Jamroz ${ }^{1}$, Matgorzata Kalisz $^{2}$, Piotr \\ Kaźmierczak ${ }^{2}$, Rafal Lusa ${ }^{3}$, and Pawet Skwierczyński ${ }^{3}$ \\ ${ }^{1}$ Gdansk University of Technology, Faculty of Civil and Environmental Engineering, Gdansk, Poland \\ ${ }^{2}$ Motor Transport Institute, Warsaw, Poland \\ ${ }^{3}$ Road and Bridge Research Institute, Warsaw, Poland
}

\begin{abstract}
Traffic management measures (vertical signs and horizontal marking, reflective elements) are used for guiding vehicles optically, indicating road mileage, marking objects in road gauge, marking vehicle and pedestrian safeguards and driver information and warning. This paper presents a synthesis of a literature study and the results of research conducted under stage one of the project LifeRoSE. The requirements for different traffic management measurements are described as well as durability and functionality tests and analysis of factors which influence durability and functionality of these measurements.
\end{abstract}

\section{Introduction}

The process of installing road safety devices on a road section has several stages. These include planning, design, construction, maintenance and removal of the devices [1]. The lifecycle of a structure involves work which includes planning and design, construction (building) and repairs, maintenance and finally demolition. In addition, these activities can be delivered at different levels of management: strategic (legislation and programming), tactical (planning and design) and operational (construction, repairs and day-to-day maintenance). Decisions that are taken at the strategic and tactical levels are important for the durability, functionality, effectiveness and costs of the devices. Today, those decisions are taken in an environment of scarcity of information, a lot of uncertainty and a lack of the right methods and tools. As a result, the decisions are far from optimal [1].

Durability is defined as the ability of a device or object to maintain its utility over time. In the case of road safety devices used on the road durability means the ability (capacity) to maintain the assumed functionality during the road object's required life. Durability and life expectancy requirements for road markings are defined in standards, guidelines and recommendations which are device-specific [2]. The life expectancy of road safety devices depends on the type and durability of manufacturing material [3], and how the devices are used. While this has been researched at length, it is not clear how the conditions of operation (weather, winter road maintenance, occurrence of micro vehicle impacts) affect the life expectancy of road devices. Road safety devices must meet a number of functional features such as safety, reliability, fitness, effectiveness, readiness, day and night-time visibility, adequacy and others. Some of the undesired problems that require research include a lack of

* Corresponding author: lukjelin@.pg.gda.pl 
methods for estimating how the type and durability of traffic management devices and operating conditions impact the functionality of the specific groups of road safety devices. Also, there are no methods for selecting the acceptability limits of how to assess the properties (functions) of devices.

The most important function of road safety devices is to protect road and roadside users from death or injury. While there has been extensive independent research into how selected factors affect the properties of road safety devices [4], this has never been a comprehensive effort.

This article describes the results of preliminary studies on the durability of horizontal and vertical marking in relation to normative requirements. The research was done in the laboratory and on test sites. This is the first stage of the research project entitled "Life cost analysis of Road Safety Elements".

\section{Testing the durability of horizontal road markings}

Horizontal markings can be divided into permanent and temporary markings, depending on their expected application. The technologies available divide the devices further into thin layer marking - with a layer of $0.30 \mathrm{~mm}$ to $0.90 \mathrm{~mm}$, thick layer marking - with a layer of $0.90 \mathrm{~mm}$ to $5.00 \mathrm{~mm}$, smooth (full), structural and profile marking. Their utility features fall into type I - not visible in wet conditions and during rainfall and type II - visible in wet conditions and during rainfall.

Figure 1 shows examples of thin and thick layer markings and of acoustic lines.
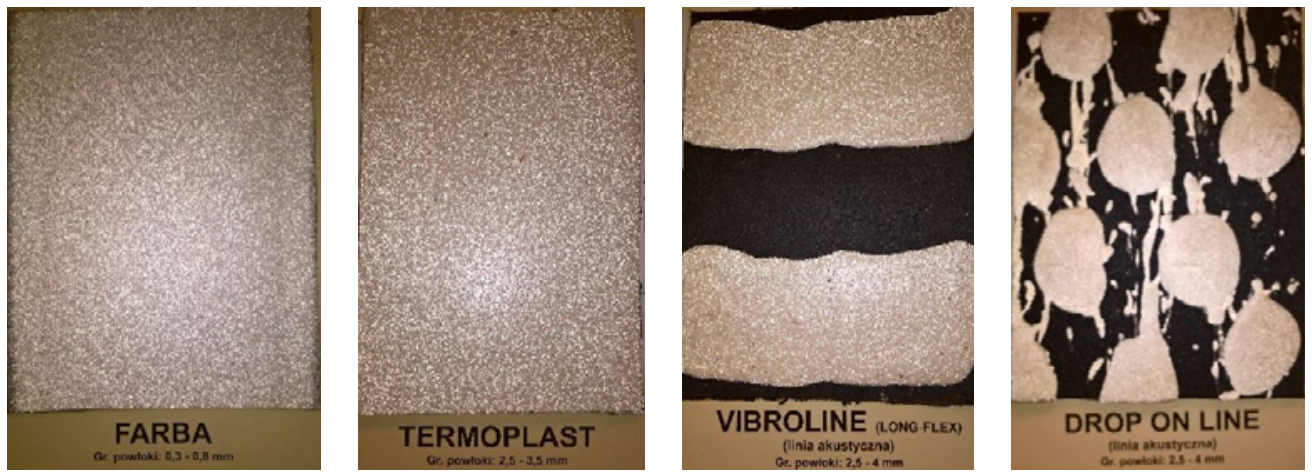

Fig. 1. Examples of horizontal markings.

To assess the durability and function of horizontal marking, the following parameters are used:

- Surface coefficient of retroreflected luminance $\mathrm{R}_{\mathrm{L}}$ (in dry and wet condition),

- Coefficient of diffuse luminance QD,

- Coefficient of $\beta$ luminance and chromaticity coordinates $\mathrm{x}, \mathrm{y}$,

- Skid resistance tester SRT,

- Class of traffic (number of times a wheel can drive over the marking).

According to the guidelines [5] marking on specific road classes should meet the parameters listed in Table 1. 
Table 1. Minimum requirements for permanent horizontal road markings.

\begin{tabular}{|l|c|c|c|}
\hline \multirow{2}{*}{\multicolumn{1}{|c|}{ Properties }} & \multicolumn{3}{c|}{ Requirements } \\
\cline { 2 - 4 } & Motorways & Express roads & Other roads \\
\hline Luminance coefficient $\beta$ & 0.32 & 0.32 & 0.30 \\
\hline $\begin{array}{l}\text { Surface coefficient of } \\
\text { retroreflected luminance } \mathrm{R}_{\mathrm{L}} \\
{\left[\mathrm{mcd}^{*} \mathrm{~m}^{-2 *} \mathrm{x}^{-1}\right]}\end{array}$ & 200 & 150 & 100 \\
\hline Skid resistance (SRT) & 50 & 50 & 45 \\
\hline Durability (on LCPC scale) & 6 & 6 & 6 \\
\hline
\end{tabular}

In Europe two methods for testing durability are used:

- assessment on an experimental section [6],

- assessment on a wear and tear simulator [7] Since 1995 Poland has been using experimental sections to test durability: DK 7, DK 5, DK 22, DK 16, and the street Jagiellonska in Warsaw.

Figure 2 shows preliminary results of durability tests of horizontal marking made using thermoplastic materials on the DK 22 experimental section. Lane 1 and lane 2 denote the line number from the edge of the carriageway in the case of the longitudinal durability test pattern [6]. Lane 1 (line next to edge of carriageway) is rarely driven over while lane 2 (line of wheels) is used heavily by traffic. Section 25 is thermoplastic material containing $40 \%$ of micro glass beads, section 27 is thermoplastic material containing $30 \%$ of micro glass beads. $\mathrm{R} 2$ and $\mathrm{R} 3$ requirements denote classes of surface coefficient of retroreflected luminance $\mathrm{R}_{\mathrm{L}}$ [8] at $100 \mathrm{mcd} \mathrm{m}^{-2} \mathrm{~lx}^{-1}$ and $150 \mathrm{mcd} \mathrm{m}^{-2} \mathrm{~lx}^{-1}$, respectively.

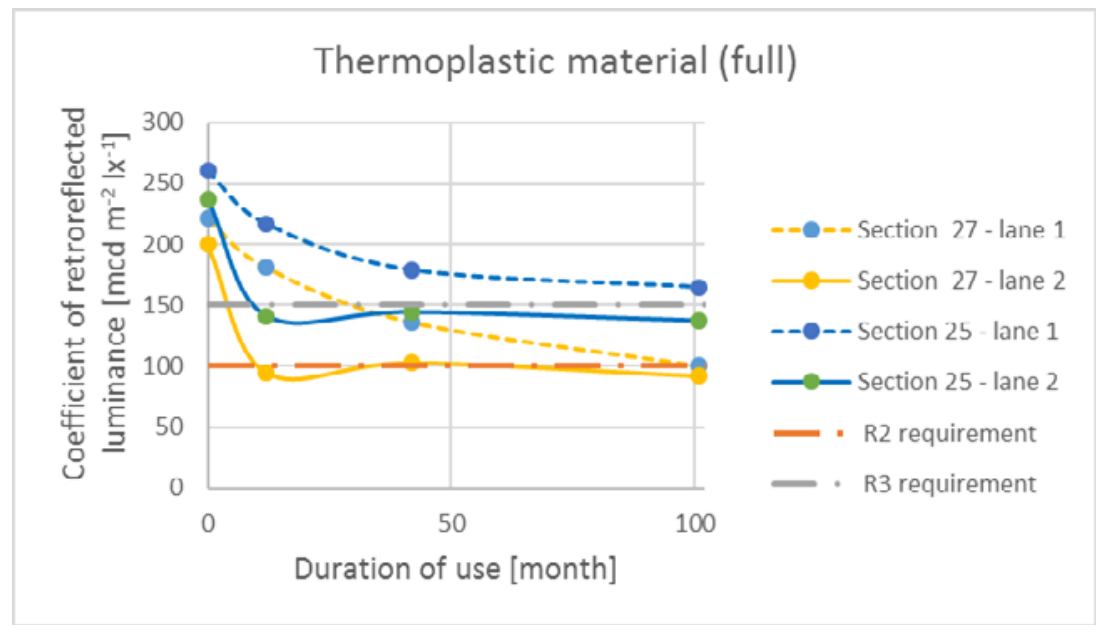

Fig. 2. Test results of retroreflected luminance $\mathrm{R}_{\mathrm{L}}$ on $\mathrm{DK} 22$ experimental section depending on how long the marking has been in use.

Figure 3 shows preliminary results of durability tests of horizontal marking made using thermoplastic materials on the DK 16 experimental section. Lane 2 and lane 3 denote the line number from the edge of the carriageway in the case of the longitudinal durability test pattern [6]. Lane 3 (line between wheel tracks) is rarely used while lane 2 (line of wheels) is used heavily by traffic. Section 26 is thermoplastic material containing $30 \%$ of micro glass beads, 
section 27 is thermoplastic material containing $30 \%$ of micro glass beads. R2 and R3 requirements denote classes of surface coefficient of retroreflected luminance $R_{L}$, at 100 mcd $\mathrm{m}^{-2} \mathrm{~lx}^{-1}$ and $150 \mathrm{mcd} \mathrm{m}^{-2} \mathrm{~lx}^{-1}$ respectively [8].

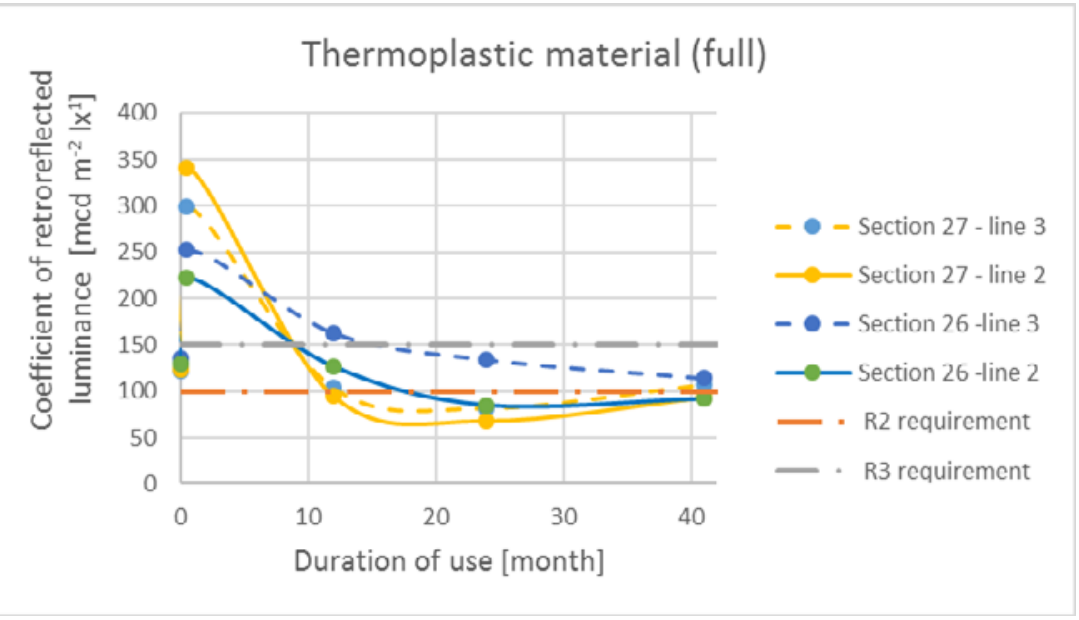

Fig. 3. Test results of retroreflected luminance $R_{L}$ on $D K 16$ experimental section depending on how long the marking has been in use.

\section{Testing the life expectancy of vertical markings}

Permanent vertical road signs are road safety devices in the form of disks and plates with information or symbols, which once installed on a road, have their front surface in upright position. The disk is a flat surface with rigid edges that carry the face of the sign. Disks are usually made of steel zinc coated sheet or powder coated aluminium or otherwise corrosion protected. The face of the sign is the sign's front part designed to inform using symbols or text. It is made of self-adhesive reflective foil, the contents is screen-printed using opaque colour or transparent paint or transparent colour foil. To ensure that the sign is visible from a distance that allows motorists to see the sign, read it and respond appropriately, signs should use reflective materials. The types of reflective materials to be used for specific locations and road class are given in Table 2 [9].

Table 2. Types of reflective foil on road signs depending on road sign location - minimum requirements [9].

\begin{tabular}{|c|c|c|c|c|c|c|}
\hline \multirow{2}{*}{$\begin{array}{c}\text { Location } \\
\text { of sign }\end{array}$} & \multicolumn{4}{|c|}{ National roads } & \multirow[b]{2}{*}{$\begin{array}{l}\text { Regional } \\
\text { roads }\end{array}$} & \multirow{2}{*}{$\begin{array}{c}\text { County } \\
\text { and } \\
\text { municipal } \\
\text { roads }\end{array}$} \\
\hline & $\begin{array}{c}\text { Motorways } \\
\text { and } \\
\text { express } \\
\text { roads }\end{array}$ & $\begin{array}{c}\text { Dual } \\
\text { carriageways }\end{array}$ & $\begin{array}{l}\text { International } \\
\text { single } \\
\text { carriageways }\end{array}$ & $\begin{array}{c}\text { Other } \\
\text { carriageways }\end{array}$ & & \\
\hline $\begin{array}{l}\text { Next to } \\
\text { carriage- } \\
\text { way }\end{array}$ & 2 & 2 & 2 & $1(*)$ & $1(*)$ & $1(*)$ \\
\hline $\begin{array}{c}\text { Above } \\
\text { carriage- } \\
\text { way }\end{array}$ & Prismatic 3 & 2 & 2 & 2 & 2 & 2 \\
\hline
\end{tabular}


Reflective foil reflects light in return reflection. Light is reflected directionally and the direction is similar to the incident direction. This property holds even for significantly different incidence directions. The physical parameter which characterises this property is luminance coefficient determined as the relation between the luminous intensity $I$ of a reflective device in the direction of observation and the value of lighting intensity $E$ on that device measured on a plane perpendicular towards the incident light $[\mathrm{mcd} / \mathrm{lx}]$. The most frequently used technologies that produce return reflection are micro glass beads (I and II generation foil) and micro prismatic (III and higher generation foil).

Table 3. Type of foil used on road signs in normal and enlarged view.

\begin{tabular}{|c|c|c|c|}
\hline \multirow{2}{*}{ View } & \multicolumn{3}{|c|}{ Type of reflective foil } \\
\hline & I generation foil (type 1) & II generation foil (type 2) & III generation foil (type 3) \\
\hline Normal & & & \\
\hline Enlarged & & & \\
\hline
\end{tabular}

Between 2005-2010 as part of technical certification, the recommendations of the Road and Bridge Research Institute (the IBDiM) were followed [10]. The Recommendations came as a set of technical and utility properties, research methods and minimal requirements to be met by vertical road signs. The Recommendations take account of the legal regulations $[9,11]$ and are related to material requirements for disks and plates, size and quality requirements, road sign and plate reflective face requirements, operating properties of foil and sign requirements.

Table 4 presents the IBDiM recommendations which also defined the types of materials for disks and plates, types of reflective foil and opaque foil used on sign faces, minimal requirements regarding the surface coefficient of foil retroreflected luminance before and after exposure to water and salt mist (measured in simplified geometry in night-time conditions), tristimulus values requirements (colour) and foil luminance coefficient before and after exposure to salt mist (measured in daylight), operating requirements for foil used on vertical signs and for vertical signs.

Table 4. Normative requirements for reflective foil and vertical signs.

\begin{tabular}{|l|l|}
\hline Reflective foil requirements & Vertical sign requirements \\
\hline adhesive power & wind resistance \\
\hline high temperature resistance & concentrated load resistance \\
\hline low temperature resistance & resistance to rotational displacement \\
\hline water resistance & permanent deformation resistance \\
\hline ball impact resistance & type of face edge \\
\hline- & drilling through sign face \\
\hline
\end{tabular}


At present, foils and signs should also be tested for foil retroreflected luminance coefficient in full geometry at night-time, resistance of plates and signs to neutral salt mist and foil durability -accelerated resistance testing of foil to weather conditions in natural and artificial conditions. Manufacturers use different service life durations for reflective foil on sign faces: for type 1 up to 3 years and for type 2 up to 5 years. Please note that in the five years of following the IBDiM Recommendations, the road sign retroreflected luminance coefficient was only tested in simplified geometry, i.e. for a single angle of observation (20') and a single angle of illumination $\left(+5^{\circ}\right)$.

\section{Testing the life expectancy of point reflective elements}

Road markings also come in the form of point reflective elements installed on the road surface as a complement to horizontal markings. They provide guidance and reflect light to warn, guide and inform road users. They can be built of one or several parts and can be stuck, anchored or inlaid. Reflective points are usually run along the shoulder, on kerbs and lines separating lanes of traffic. Their basic objective is to show how the road runs especially on bends, curves and other sites that require more driver concentration (so called light guidance). Reflective points (permanent and temporary) are tested to ensure comparability and reproducibility of test results. Tests are made on site. The standard [12] gives an exact definition of the requirements to be met by test road sections, weather conditions, traffic volume and type of surface. The standard also defines the minimal time of the test on an experimental road section: at least one year for permanent elements and at least four months for temporary elements. Road tests are conducted in five stages.

1. Assessment of day visibility:

- check envelope profiles of all elements for sharp edges from traffic side as a result of damage, rubbing or separation,

- check the elements for integrity, if there are less than 45 elements the test is considered invalid,

2. Assessment of night visibility:

- check the roadway elements for luminance when lit up with headlights; permanent elements are tested from a distance of $50 \mathrm{~m} \pm 3 \mathrm{~m}$ while temporary elements are tested at $20 \mathrm{~m} \pm 2 \mathrm{~m}$.

3. Photometric tests, i.e. tests of the retroreflective coefficient and luminance coefficient (for temporary elements only) using elements from experimental sections.

Table 5. Classification of utility properties of point reflective elements in the standard.

\begin{tabular}{|l|l|}
\hline \multicolumn{1}{|c|}{ Basic assessment: } & \multicolumn{1}{c|}{ Night visibility: } \\
\hline Class S0 - unidentified properties & Class R0 - unidentified properties \\
\hline $\begin{array}{l}\text { Class S1- 42 and more of remaining } \\
\text { elements }\end{array}$ & $\begin{array}{l}\text { Class R1 - average value of reflection coefficient } \mathrm{R} \\
100 \% \text { of the requirement or more }\end{array}$ \\
\hline $\begin{array}{l}\text { Class S2 - from 35 to 41 of remaining } \\
\text { elements }\end{array}$ & $\begin{array}{l}\text { Class R2 - average value of reflection coefficient } \mathrm{R} \\
\text { from } 50 \% \text { to } 99 \%\end{array}$ \\
\hline $\begin{array}{l}\text { Class S3 - from 1 to 34 of remaining } \\
\text { elements }\end{array}$ & $\begin{array}{l}\text { Class R3 - average value of reflection coefficient } \mathrm{R} \\
\text { from } 20 \% \text { to } 49 \%\end{array}$ \\
\hline- & $\begin{array}{l}\text { Class } \mathrm{R} 4-\text { average value of reflection coefficient } \mathrm{R} \\
\text { from } 1 \% \text { to } 19 \%\end{array}$ \\
\hline- & Class R0 - unidentified properties \\
\hline
\end{tabular}


Table 6 lists examples of test results for point reflective elements which the Motor Transport Institute has conducted so far.

Table 6. Motor Transport Institute test results for point reflective elements.

\begin{tabular}{|c|c|c|}
\hline Year of test / service life & Basic assessment & $\begin{array}{c}\text { Night visibility } \\
\geq \mathbf{1 5 0 m c d} / \mathbf{l x}\end{array}$ \\
\hline $2010 / 18$ months & $50 / 50$ class $\mathrm{S} 1$ & $8.7 \mathrm{mcd} / \mathrm{x}$ class R4 \\
\hline $2011 / 12$ months & $50 / 50$ class S1 & $9.0 \mathrm{mcd} / \mathrm{l}$ class R4 \\
\hline $2014 / 14$ months & $47 / 50$ class S1 & $44.6 \mathrm{mcd} / 1 \mathrm{x}$ class R3 \\
\hline $2014 / 14$ months, device with ceramic layer & $47 / 50$ class S1 & $260.2 \mathrm{mcd} / 1 \mathrm{x}$ class R1 \\
\hline 2014 / 14 months, device in cast iron cover & $48 / 50$ class S1 & $61.6 \mathrm{mcd} / 1 \mathrm{x}$ class R3 \\
\hline $2014 / 12$ months, device in cast iron cover & $47 / 50$ class S1 & $11.0 \mathrm{mcd} / 1 \mathrm{x}$ class R4 \\
\hline
\end{tabular}

\section{Summary}

Tests of traffic management devices vary from group to group. The life expectancy and functionality of the devices depends on a variety of factors. The research project LifeRoSE (Life cost analysis of Road Safety Elements) will continue its research on how the function of road traffic devices changes with new samples and test sites to come.

\section{Acknowledgements}

Research conducted under a project implemented within the RID programme, funded by the Polish National Centre for Research and Development and the General Directorate for National Roads and Motorways in Poland, for the years 2016-2019.

\section{References}

1. K. Jamroz, Method of risk management in highway engineering. Metoda zarządzania ryzykiem w inżynierii drogowej (Gdansk University of Technology, 2011)

2. G.B. Thomas, C. Schlotz, Durable, cost-effecitve pavement markings. Iowa DOT Project TR-454 (Annes, Iowa, USA, 2001)

3. D. Marzougui, U. Mahadevaiah, F. Tahan, C.D. Kan, R. McGinnis, R. Powers, Guidance for selection, use and maintenance of cable barrier system. NCHRP Raport 711 (Transport Research Board, Washington, USA, 2012)

4. K. Jamroz, M. Budzyński, W. Kustra, L. Michalski, S. Gaca, Tools for road infrastructure safety management - Polish experiences, in: Transp. Res. Procedia, pp. 730-739 (2014). doi:10.1016/j.trpro.2014.10.052

5. Z. Szczepaniak, Vademecum poziomego oznakowania dróg. (IBDiM, Warsaw, 2015)

6. $\quad$ BS EN 1824:2011 Road marking materials. Road trials (2011)

7. BS EN 13197:2011+A1:2014 Road marking materials. Wear simulator Turntable (2011)

8. BS EN 1436:2007+A1:2008 Road marking materials. Road marking performance 
for road users (2007)

9. Regulation of the Minister of Infrastructure of 3 July 2003 on detailed technical conditions for road signs and signals and traffic safety devices and on the conditions for their location on the road, OJ 2003 No. 220 Pos. 2181 as amended (Poland, 2003)

10. Z. Szczepaniak, Stałe odblaskowe znaki drogowe, urządzenia bezpieczeństwa ruchu drogowego U3, U4, U6, U7, U8, U9, U20, U21, U26, U27, oraz znaki dodatkowe AT, BT, R i W. Zalecenia IBDiM do udzielania Aprobat Technicznych Nr Z/200503-009, in: (IBDiM, 2005)

11. PN-EN 12899-1:2010 Fixed vertical road traffic signs. Part 1: Fixed road signs (Poland, 2010)

12. PN-EN 1463-2:2003 Horizontal marking materials - Point reflective elements - Part 2: Field research (Poland, 2003) 